\title{
UM ANGOLANO NA ITÁLIA E UM ITALIANO EM ANGOLA: DIFERENTES FORMAS DE EXÍLIO
}

\author{
AN ANGOLAN IN ITALY AND AN ITALIAN IN ANGOLA: \\ DIFFERENT WAYS OF EXILE
}

Paulo Henrique Pappen ${ }^{1}$

RESUMO: Este texto é uma reflexăo sobre ser estrangeiro, a partir da comparaçăo entre o filme Perdidos na África (AGE, SCARPELLI e SCOLA, 1968) e o livro de poemas Tempo angolano em Itália (COSTA ANDRADE, 1963). O filme é italiano, mas se passa em Angola, e o livro foi escrito por um angolano exilado na Itália. Estabelece-se assim uma relaçăo complementar entre os estrangeiros apresentados pelas duas obras, bem como diversos pontos de vista reveladores do outro e de dimensóes como o espaço e o tempo.

Palavras-chave: estrangeiro; exílio; imagologia.

ABSTRACT: This paper is a reflection on being foreigner, based on a comparison between the film Will our heroes be able to find their friend who has mysteriously disappeared in Africa? (AGE, SCARPELLI e SCOLA, 1968) and the book Tempo angolano em Itália (COSTA ANDRADE, 1963). The film is Italian, but takes place in Angola, and the book was written in Italy by an Angolan poet. Therefore, there is a complementary relation between the foreigners presented by the film and the book, revealing also different points of view about notions such as alterity, and space and time dimension.

Keywords: foreigner; exile; imagology.

\section{INTRODUÇÃO}

Este texto é sobre ser estrangeiro. Mais especificamente, ser estrangeiro na Itália e em Angola, dois países muito diferentes um do outro, mas náo tăo diferentes a ponto de um angolano nâo conseguir fazer amigos na Itália e vice-versa. Isto é, pessoas săo pessoas em qualquer parte deste planeta, e basta um nível razoável de tolerância para que qualquer ser humano viva em qualquer sociedade. Obviamente, a tolerância deve ser recíproca. Quando uma sociedade náo tolera determinado indivíduo, na melhor das hipóteses ele será exilado ou obrigado a exilar-se, pois ele é o lado mais fraco na disputa criada pela intolerância.

Por tolerância entendo năo apenas "respeito pelo outro", mas sobretudo "noçăo de que o outro também pode ser interessante". A rigor, năo existem estrangeiros, mas somente amigos que a gente ainda náo conheceu.

Universidade Federal de Santa Catarina / paulohpappen@gmail.com 
Esse é um ponto de vista presente nas duas obras analisadas aqui, quais sejam, Tempo angolano em Itália (1962), livro de poemas de Costa Andrade, e Perdidos na África (1968), filme de Age, Scarpelli e Scola.

Dependendo da situaçăo, a denominaçâo "estrangeiro" ganha diferentes tons, mas năo pretendo entrar em detalhes semânticos. Me interessa, sobretudo, o fato de que "estrangeiro" vem de "estranho", ou seja, o estrangeiro é aquele que, de alguma forma, gera estranhamento, seja por ser forasteiro, seja por ser "diferente".

Neste texto, vou usar o termo com o sentido já dicionarizado, isto é, estrangeiro é aquele que năo pertence ou que se considera como năo pertencente a uma regiăo, classe ou meio. Percebo nessa definiçăo tanto a noçăo técnica, jurídica, quanto a psicológica, poética. Ajunto, apenas, que existem níveis de estrangeiros, que văo desde o turista, passam pelo imigrante e chegam ao exilado, aquele que năo pode voltar para casa por questóes políticas - ou seja, tomo o sentido restrito de exilado. E claro, poeticamente podemos todos nos considerar estrangeiros, sobretudo com relaçăo a grupos sociais distintos, com os quais precisamos conviver em uma metrópole, por exemplo.

É uma característica clássica dos poetas se sentirem deslocados, incompreendidos e desprezados por seus contemporâneos. É uma sensaçāo legitimada pela História, que motivou tantos autoexílios: "afinal de contas", pensa o poeta, "se me sinto exilado no meu próprio país, por que năo partir para o exterior, onde ao menos serei estrangeiro de verdade e poderei reclamar e fazer arte com base em experiências absolutamente novas e estranhas a cada dia?". O artista, no exílio, pode até se sentir melhor do que em casa. Pode, enfim, se sentir em sua verdadeira casa, porque tem fontes diárias de inspiraçâo, jamais fica entediado, reclamando que năo acontecem coisas novas em sua rotina. Como disse Ying Chen, escritora chinesa que vive no Canadá: "Meu verdadeiro lar está onde me torno aquilo que quero ser" (CHEN apud PATERSON, 2007, p. 20). Tudo no exílio é novo e o exilado pode se recuperar do estranhamento fazendo algum tipo de arte, exorcizando a dor. Esse é o "exílio ideal", vivido por artistas e poetas americanos nos anos 20 em Paris e, em certo sentido, é também a situaçâo vivida por um dos personagens do filme discutido neste trabalho, personagem que, nos anos 60, foi se aventurar na misteriosa África e nunca mais quis voltar à tediosa Europa.

O caso do poeta angolano, também objeto desta reflexăo, é relativamente diferente, pois ele é um exilado político que vai para a Europa e tem esperança de retornar ao seu país. De certa forma, ele tem certeza de que esse retorno se realizará. Talvez se possa dizer que o seu exílio signifique buscar dignidade no exterior, mas ter de conviver com a sensaçăo de estar sendo egoísta - o homem salvo no estrangeiro, enquanto seus irmáos morrem na terra natal. Entăo, a comparaçăo que estabeleço aqui é entre um angolano exilado politicamente na Itália e um italiano exilado poeticamente em Angola. Em outras palavras: o africano vai para a Europa por náo poder ser livre na África e o europeu vai para a África por querer ser livre de outra maneira, uma maneira impossível na Europa.

As obras comparadas tratam diretamente da questăo de ser estrangeiro, apresentando diferentes maneiras de sê-lo, formas que refletem naturalmente os diferentes contextos histórico-sociais enfrentados pelos seus personagens/autores. 


\section{UM PONTO DE VISTA ITALIANO}

Como os italianos veem os estrangeiros? Uma boa resposta foi dada por Bollati (1983, p. 1):

O estrangeiro é visto como um fantasma, como uma apariçăo. A civilizaçăo clássica expressou um etnocentrismo de grande dimensâo histórica, estabelecendo uma separaçấo evidente entre aqueles que pertenciam à área greco-latina e aquela humanidade duvidosa que năo pertencia a essa área, isto é, os "bárbaros".

Os italianos carregam consigo a sombra de uma história gloriosa, que se confunde com a história da civilizaçâo ocidental. O "melhor momento" da Itália já passou. É um país velho, um museu vivo que se despedaça a olhos nus. Os italianos vivem o dilema de ter que fazer a manutençâo da História ao mesmo tempo em que precisam acompanhar a evoluçâo dela, o que significa destruir rastros do passado. Só que há muito tempo a Itália nāo é protagonista, nāo encabeça a direçâo do "progresso". O fascismo foi uma terrível reaçấo a essa crise de identidade. Foi uma tentativa de extirpar à força o complexo de inferioridade originado pela sombra do passado glorioso. Como disse Bollati (1983, p. 2):

O caráter é a forma pela qual um grupo étnico tende a representar a si mesmo, respondendo à necessidade de construir e defender a própria identidade, necessidade que surge na presença de um outro grupo, cuja diversidade constitui um perigo existencial: a identidade mesma se define pela diferença e se baseia na desvalorizaçăo ou negaçấo da identidade do outro.

Na Itália da primeira metade do século XX, "o inimigo maior" era a sociedade urbana consumista que se desenvolvia, sobretudo, nos EUA e que rapidamente se espalhava pelo resto do mundo, sem perguntar a opiniăo de ninguém. Logo, era preciso se reafirmar: "Somos um povo camponês, humilde, que valoriza a família, a igreja católica e a sesta depois do almoço!" E como sempre acontece, quando năo temos argumentos para convencer alguém de que estamos certos (e isso já devia servir para nos alertar de que nâo temos razăo), partimos para a negaçăo, para o menosprezo: “O mundo está virando um lugar indecente! Precisamos resgatar a tradiçăo!" Discursos vazios sâo bastante comuns quando alguém é assertivo demais.

Para os fascistas, nada mais útil à própria afirmaçăo do que a fundaçăo de um império (na África, essa "terra de ninguém"). O Reino da Itália já possuía colônias no continente (Líbia, Somália, Eritreia) desde o fim do século XIX. Houve inclusive a tentativa de "roubar" Angola dos portugueses, durante as negociaçōes do Tratado de Versailles, em 1919. Mas foi depois de dominar a Etiópia, em 1936, que a Itália se proclamou Império. Durou até 1943, quando o exército britânico derrotou as tropas italianas na África, culminando com o Tratado de Paris, em 1947, que tirou o direito de a Itália possuir qualquer colônia. A Somália, porém, permaneceu sob administraçâo italiana reconhecida pela ONU até 1960.

Criar um império, afirmar-se como maior e melhor, basear-se em discursos nacionalistas săo exemplos de criaçăo de caráter (mesmo que mau-caráter), geraçăo de identidade através da diferenciaçăo paranoica que somos capazes de fazer entre "nós" e "os outros". Óbvio que existem diferenças culturais entre os povos, mas o ponto de partida da política revela a identificaçăo das diferenças apenas para anulá-las. Até parece que somos incapazes de buscar, antes de tudo, as semelhanças existentes entre "nós" e "os 
outros". É como se o que houvesse de parecido năo servisse para nos reconhecermos a nós mesmos. E é como se reconhecer a nós mesmos fosse mais importante do que nós perdermos, nos mesclarmos entre os outros.

Por isso que é tăo interessante a escolha de Titino, o italiano perdido na África. Sua escolha dá, logo de início, a ideia de que năo somos italianos, portugueses, angolanos, gaúchos, mas sim gente, seres sociais capazes de se adaptar a culturas e situaçôes diversas, sem necessidade de um rótulo identitário oficial.

Age e Scarpelli formaram uma dupla de roteiristas italianos de grande criatividade. Alguns importantes filmes de sua autoria săo Os eternos desconhecidos (1958, com direçâo de Mario Monicelli), Os monstros (1963, direçâo de Dino Risi) e Nós que nos amávamos tanto (1974, com direçăo de Ettore Scola, autor e diretor também do filme em questăo aqui).

O título, Riusciranno i nostri eroi a ritrovare l'amico misteriosamente scomparso in Africa?, pode ser traduzido como "Será que os nossos heróis văo conseguir reencontrar o amigo misteriosamente desaparecido na África?" Ou seja, logo se percebe que se trata de uma comédia. Em Portugal, porém, o título ficou Um italiano em Angola, nome neutro até demais. No Brasil ficou Perdidos na África, que tem ainda um toque de comédia, mas sem a ironia do original. Entretanto, nos três títulos fica mais ou menos evidente que se trata da aventura de um europeu no continente africano, essa parte do mundo considerada quase tăo insondável quanto outro planeta.

Basicamente, é a história de um italiano, Fausto Di Salvio (representado por Alberto Sordi), que vai a Angola procurar Titino (Nino Manfredi), um compatriota que está sumido, talvez morto. Depois de várias peripécias e perambulaçōes, Fausto encontra Titino no deserto, onde ele é feiticeiro de uma tribo. Fausto tenta convencê-lo a retornar à Itália, mas Titino decide permanecer em Angola, onde se sente mais em casa.

\section{UM PONTO DE VISTA ANGOLANO}

Pensar em estrangeiro, na Angola da metade do século XX, era pensar principalmente nos colonizadores portugueses, que procuravam sobrepor as culturas nativas. Entăo, a tarefa intelectual angolana era năo se deixar perder, descobrir seu próprio ponto de vista, sua própria identidade, conforme o lema "Vamos descobrir Angola!", lançado no fim dos anos 40 por Viriato da Cruz e Agostinho Neto, entre outros criadores do movimento Novos Intelectuais de Angola. Na continuidade desse movimento, foi criada a revista Mensagem, cuja primeira ediçăo, em 1951, trazia o editorial abaixo:

"MENSAGEM" será a síntese de todas as mensagens de amor, de fraternidade e de esperança, que nós, os jovens de Angola, dirigimos a todos os nossos irmăos e a todos os jovens do Mundo, - porque é na generosidade da Juventude que fundamentamos os nossos anseios. E a mocidade, a despontar para a Vida, qual botăo de rosa a desabrochar em mil promessas de carinho, saberá ouvir-nos; ouvir-nos e compreender-nos; compreender-nos e ajudar-nos. Porque será da compreensâo da gente moça que resultará a Obra Mestra que nós desejamos" (MENSAGEM, 1951, p. 1 apud SANTOS, 2013)².

Me refiro à revista Mensagem publicada em Angola, e náo à Mensagem - A voz dos naturais de Angola, publicada em Portugal. 
Nota-se que era uma revista-manifesto, uma obra fundamentalmente política: apelando à fraternidade, estava-se lutando contra o fascismo, ao mesmo tempo em que se dizia "nós somos generosos, nós amamos", em contraposiçâo à força cruel dos colonizadores.

Dentro da revista, poemas como Mamá negra, de Viriato da Cruz, anunciavam uma proposta estética, mais que angolana, negro-africana:

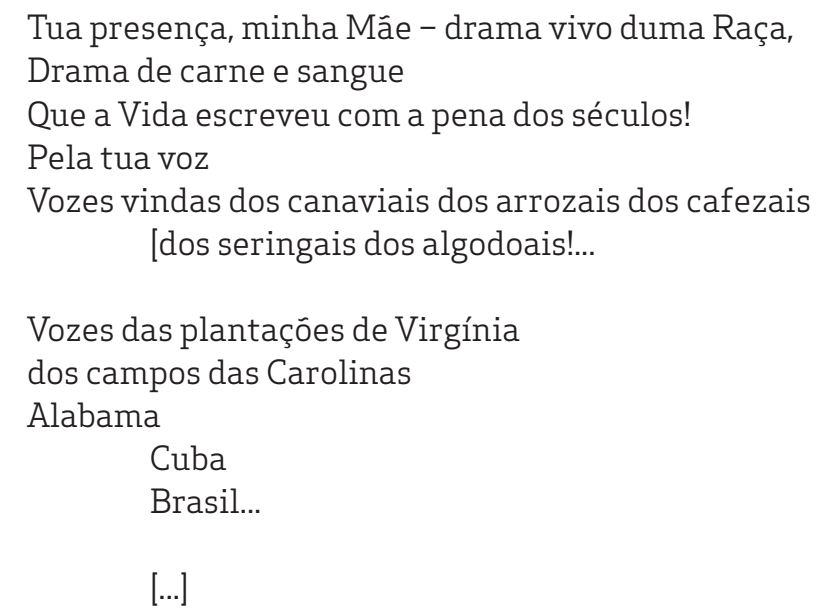

Pelos teus olhos, minha Mãe

Vejo oceanos de dor

Claridades de sol-posto, paisagens

Roxas paisagens

Dramas de Cam e Jafé...

Mas vejo (Oh! se vejo!...)

mas vejo também que a luz roubada aos teus

[olhos, ora esplende

demoniacamente tentadora - como a Certeza...

cintilantemente firme - como a Esperança...

em nós outros, teus filhos,

gerando, formando, anunciando -

o dia da humanidade

O DIA DA HUMANIDADE!...

(CRUZ, 2013)

As referências à máe negra revelam a matriz comum de grande parte do mundo, um mundo que sofre pela opressăo racial, principalmente, e que, apesar de tudo, mantém sua voz, sua alma, seu olhar - sinais da vida, impossíveis de abafar -, manifestando a esperança, a certeza de que a liberdade triunfará. Fica evidente que a preocupaçáo dos poetas de Mensagem é universal e que, portanto, năo se definirá o que é ser angolano através da depreciaçăo do outro. Ser angolano, antes de mais nada, é ser gente. É só o que se pede: humanidade.

Essa temática se acentua na revista Certeza ${ }^{3}$ (1957), da qual Costa Andrade, o poeta comentado neste texto, faz parte. Nessa publicaçâo, ressaltam-se os "temas

3 Me refiro à revista Certeza publicada em Angola, publicada até 1961, e nấo à revista Certeza caboverdiana, de 1944. 
da identidade, da fraternidade, da terra de Angola pátria de todos, negros, brancos e mestiços" (COSTA, 2006). Ou seja, a dignidade humana está além de qualquer questão racial: a discussâo aqui se dá mais em termos de opressores e oprimidos. Um discurso marxista, enfim, bastante alentador para os intelectuais africanos (brancos, como Costa Andrade, ou negros, como Agostinho Neto) que viam seu povo escravizado e precisavam encontrar alguma esperança.

Entâo, se Mensagem tentava buscar o apoio dos jovens para a construçáo de um futuro digno, Certeza já oferece alguma indicaçāo de que esse futuro é possível, ou melhor, inevitável. É o que se lê nos versos Francisco Fernando da Costa Andrade (1936 2009), poeta, guerrilheiro angolano (foi também deputado, quando voltou para Angola, depois da independência daquele país), que em 1962 andou exilado pela Europa, mais precisamente pela Itália. "Tempo angolano em Itália" é fruto desse período, um livro de poemas com temática política: os poemas correm em um clima de reivindicaçâo da liberdade e veneraçăo da resistência. Esses dois conceitos sâo básicos: a resistência italiana durante o fascismo e a liberdade conquistada servem de inspiraçấo ao angolano, que almeja o mesmo espírito de bravura para o seu povo.

\author{
Năo acredito \\ que este povo que venera a Resistência \\ seja contra a liberdade \\ (A liberdade \\ náo conhece a geografia do fascismo \\ a liberdade năo conhece \\ franco e salazar) \\ A liberdade é a raiz da Resistência: \\ Resistência italiana \\ cubana \\ ou argelina. \\ A Resistência de Angola. \\ Este povo está conosco eu sei \\ mas náo basta que eu o saiba. \\ Confirmem-no os que podem \\ claro e forte. \\ A vocaçáo africana apregoada \\ será depois uma verdade \\ estreitando as nossas mâos.
}

(ANDRADE, 1963, p. 73)

\title{
RELAÇÕES ENTRE AS OBRAS
}

O que logo chama a atençăo é a questăo da angústia do tempo, que é representado pelo relógio, na Itália, e pelo sol, em Angola. O tempo é mecânico na "civilizaçăo" e natural na "selva".

Isso é demonstrado já nas primeiras cenas/palavras de ambas as obras. Em Perdidos na África, um relógio, um engarrafamento, um homem de terno dentro de um carro em um dia de sol, dăo um clima angustiante insustentável. Fausto Di Salvio, o protagonista, só respira quando desembarca em Angola, e aí a história inteira ganha leveza 
(inclusive a música-tema aumenta de volume e se harmoniza com os sons da selva). De forma parecida começa o livro de Costa Andrade: "Náo consegui dormir a noite inteira / O relógio só me falou das horas" (ANDRADE, 1963, p. 9). Aqui também há um relógio, esse ladrăo de sono. E, em vez de uma cena que se passa em um carro apertado, como no filme, o poema se passa em um trem cheio de gente estranha que vai na direçăo de uma fronteira. Sempre a angústia, que ataca por todos os lados: o desconforto do espaço e a ânsia do tempo.

A partir da chegada dos italianos em Angola, a angústia passa a se alternar com o alívio, e o mesmo se percebe nos poemas de Costa Andrade. No caso do filme, isso se dá pelo modo de vida angolano, que é apresentado como "mais próximo da natureza", portanto mais livre e tranquilo (valores que um italiano urbano aprecia bastante). As tomadas săo quase todas externas, entăo o sol é praticamente onipresente. O relógio, ali, perde seu poder para a luz natural. Já em Tempo angolano em Itália, a angústia é aplacada pelas amizades que o poeta faz e pela história da resistência italiana ao fascismo, que Costa Andrade louva esperançoso de que o espírito libertário se repita entre sua própria gente. E claro, naqueles momentos em que a vida se revela maior do que podemos compreender, o tempo mecânico perde sentido:

\author{
(...) entre as casas velhas da praia caiu a tarde \\ deixando cores fugazes sobre a areia \\ as nuvens tintas da queda inútil do tempo \\ permanecem \\ como enamoradas da hora calma excepcional
}

(ANDRADE, op. cit., p. 63)

Outro ponto chave da comparaçăo que proponho é a visăo do nativo sobre o estrangeiro. A cena em que Fausto Di Salvio, de câmera na mâo, é filmado por um angolano com uma câmera maior ainda, exemplifica bem esse aspecto, mostrando que o estrangeiro pode ser muito mais bizarro do que qualquer nativo jamais seria para um turista. Em outras palavras, o forasteiro exerce mais curiosidade sobre o autóctone do que o autóctone sobre o forasteiro. É uma surpresa com a qual todo viajante se depara, e quanto mais longe se vai, mais estranho se é. Essa jornada no desconhecido acaba sendo sempre transformadora, pois aprofunda o autoconhecimento, reflexo da visăo do outro. Ser estrangeiro, mais do que nos mostrar como os outros nos veem, nos ajuda a descobrir como nós vemos os outros.

É de se pensar que, nos anos 60, a chegada de um estrangeiro em Angola significasse algo bem diferente da chegada de um estrangeiro na Itália. No primeiro caso, o estrangeiro era provavelmente um colonizador. No segundo caso, provavelmente um imigrante ilegal. Em ambas as situaçōes, como se vê, a possibilidade de conflito é grande: em Angola, os usurpadores e os escravos; na Itália, os patrôes e os explorados. Todos sob o regime do medo. O colonizador com medo do nativo, o nativo com medo de nunca mais ser livre, o patrăo com medo do comunismo e o imigrante com medo de ser preso. Por essas e outras razôes, Costa Andrade louva a solidariedade entre os povos: liberdade é uma questăo universal. Năo ter medo (năo mais do que o medo de si mesmo, necessário para contrapor os longos voos a que a vaidade é propensa) é problema de todo mundo. 
Estranhar, muitas vezes, é sinônimo de năo gostar. Mas também pode ser um estímulo à curiosidade, ao interesse pelo outro. É uma questăo de "educaçâo":

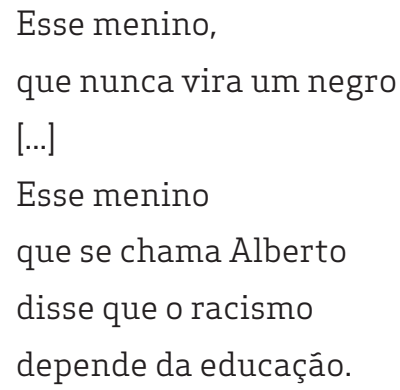

(ANDRADE, op. cit, p. 69)

O racismo também é um ponto de relaçăo entre as obras. Do filme, basta lembrar a cena em que um caçador português diz que năo é "irmăo de negro", o que ofende Fausto (nâo tanto, porém, quanto o comportamento de outro português, que fez com que homens angolanos sustentassem uma ponte nas costas para ele passar com o carro). 0 poema recém-citado fala por si só. Crer que uma pessoa seja "superior" ou "inferior" com base em argumentos de "raça" (ou gênero, idade, sexo, tamanho etc.) é uma questâo de "má educaçăo", ou seja, uma educaçâo para o mal, para aquilo que gera sofrimento. Essa educaçăo, que podemos chamar também de caráter, de virtude, náo depende necessariamente de conhecermos algum estrangeiro, seja branco, negro, homossexual ou anăo (nada será extraordinário se aprendermos cedo que tudo é extraordinário), mas o contato com o que for julgado diferente por questóes de território ou de discurso dominante seguramente contribui para, pelo menos, a tolerância. Tanto o filme quanto o livro apresentam esse tom conciliatório.

Costa Andrade faz diversas comparaçōes entre a Itália e Angola. É inevitável. Com os olhos, ele vê as cidades italianas, mas tudo, sobretudo a diferença, faz recordar Luanda.

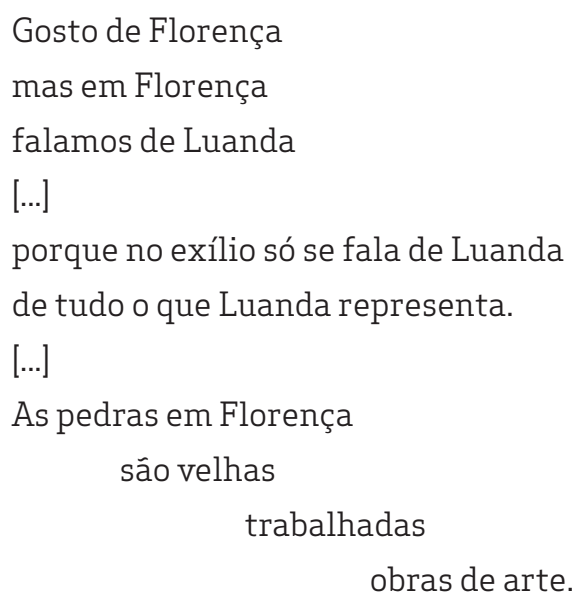

Em Luanda as pedras năo săo pedras, săo os corpos

(ANDRADE, op. cit., pp. 37-8) 
Sente-se, já na superfície do poema, que o poeta encontra solidariedade no exílio: as pessoas querem saber o que se passa em seu país e apoiam a causa da independência. Essa imagem das pedras, também, é bastante significativa: em Florença (como em Roma, Perugia, qualquer cidade italiana), as coisas estăo "acomodadas" (pela História, pela democracia, pelo bem-estar social), enquanto que em Luanda está tudo sendo feito com a vida, a morte, o sangue das pessoas.

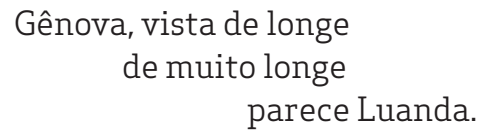

\author{
A forma a cor o mar \\ e as esperanças da gente que trabalha no porto. \\ Mas Gênova nâo é Luanda \\ nem se parece com Luanda. \\ Em Gênova a polícia disparou em Julho. \\ Em Gênova a montanha e a cidade săo antifascistas.
}

Os antifascistas foram condenados.

Em Luanda disparam os polícias em Fevereiro, Março, dos colonos.

[meses, anos, os soldados, os colonos, os filhos dos colonos e os netos

Os angolanos săo mortos.

(ANDRADE, op. cit., p. 57)

Ou seja, a guerra em Gênova (e em Roma etc.) é ocasional, servindo "apenas" para evitar o renascimento do fascismo ("Julho", no poema, faz referência aos protestos antifascistas ocorridos em 30 de julho de 1960, em Gênova). Em Luanda, por outro lado, a luta antifascista nâo dá sinais de que vai acabar tăo cedo. Além do mais, enquanto na Itália os antifascistas serâo, no máximo, presos por "vandalismo", em Angola nâo há apelaçâo.

Costa Andrade faz ainda outra comparaçâo usando Gênova:

$[\ldots]$

A cidade é morena

cor de azeitona

sorriso claro

aberto, quase inocente

- năo chega a ser morena como tu, querida.

Tu és flor de baobá

sombra de obó

e mais ainda

essa força nossa

que primeiro foi mistério

depois exotismo

mais tarde negritude

hoje é terceiro mundo.

(ANDRADE, op. cit., p. 59-60) 
É uma comparaçăo mais profunda, que trata das cores de Gênova e de Angola, e parece impossível ao poeta falar da sua terra sem mencionar a visâo estrangeira sobre ela. É interessante essa evoluçáo, que vai do mistério que coloria a África, passa pelo exotismo, com seus tons surpreendentes, ultrapassa a negritude com suas nuances antropossociológicas e assume finalmente as gradaçóes acinzentadas da política internacional, que junta tudo que "sobra" sob o rótulo de terceiro mundo.

Essa força da África, seja "mistério", "negritude" ou "terceiro mundo", foi capaz de comover estrangeiros como Fausto e Titino, o italiano perdido na África. Esse último, evidentemente, se comove mais do que o primeiro. Mas isso talvez se deva ao fato de que Titino, desde antes de se deixar seduzir pela África, já trazia em si a necessidade de escapar da apatia alternada ao frenesi que caracteriza a "civilizaçâo" ("Será que devemos admitir que nos tornamos estrangeiros num outro país porque já o somos por dentro?" KRISTEVA, 1984, p. 22). Como o filme acompanha Fausto e, até o final, năo sabemos onde está Titino, vamos aos poucos fazendo o caminho contrário desses versos recém-citados. Isto é, Fausto parte para a África encarando-a como terceiro mundo. Conforme vai se aventurando no continente, percebe que todos, ou quase todos, săo negros e que existem traços que de fato diferem a cultura negra da sua, branca, o que podemos chamar de negritude. E quanto mais se aprofunda, Fausto vai se deixando influenciar pela beleza das pessoas, pelos ritmos, pelas roupas ou falta delas, enfim, pelo exotismo. Entăo, quando finalmente encontra o cunhado, ele se descobre envolvido pelo mistério: como é possível que existam tribos no meio do deserto? Beber leite de macaca? Rezar para que chova e, milagrosamente, chover?

É realmente misteriosa essa opçăo de Titino. Ele é aquele que "largou tudo por nada", talvez um louco, para além do idealista que "larga tudo por tudo". O filme apresenta um percurso vacilante, quase aleatório do italiano desaparecido. Insatisfeito (ou facilmente satisfeito), ele vai conforme bate o vento. "Disponível, liberado de tudo, o estrangeiro nada tem, năo é nada. Mas está pronto para o absoluto, se um absoluto pudesse elegê-lo" (KRISTEVA, 1984, p. 20). E eis que o absoluto o elege feiticeiro de uma tribo.

Outros podem dizer que Titino é charlatăo. Afinal de contas, como seria possível um italiano virar xamá em Angola? Bom, é uma aposta da tribo, que acolheu o forasteiro. Ele está entre amigos. A desconfiança e a maldade săo raciocínios europeus. Mas claro: se o bruxo disser que vai chover, e náo chover, ele será comido pela tribo.

Ainda Kristeva (1984, p. 14):

"De bom grado ele sente uma certa admiraçáo para com os que o acolheram, pois em geral acredita serem eles superiores, seja material, política ou socialmente. Ao mesmo tempo, năo deixa de julgá-los um pouco limitados ou cegos". Isso vale tanto para Perdidos na África quanto para Tempo angolano em Itália. O poeta africano dedica vários versos de admiraçáo ao antifascismo italiano, como exemplo a ser seguido. Titino, também admirado, náo pode mais abandonar a tribo, pois desenvolveu outro modo de pensar e foi reconhecido como parte (importante) dela. Mas sim, os habitantes do deserto sáo talvez ingênuos - permitir que um aventureiro europeu seja seu guia? Devem estar desesperados (năo tanto, porém, quanto o próprio aventureiro). E quanto a esses italianos, simpatizantes da causa libertadora de Angola, o que eles sabem da realidade angolana? 
Dessas questôes podemos depreender algo fundamental: a "ingenuidade" dos amigos angolanos de Titino gera solidariedade, talvez ternura, e a "cegueira" dos amigos italianos do poeta gera ansiedade, talvez irritaçăo.

O feiticeiro está entre aqueles que ele pode ajudar, e pelos quais será ajudado. 0 poeta guerrilheiro está impotente entre os desarmados. "Năo há o que fazer na Europa", nisso ambos concordam. Entâo o italiano permanece na África, e o angolano só pensa em voltar para casa. Essa é certamente a maior relaçăo entre as duas obras comentadas.

\section{ALGUMA CONCLUSÃO}

O estrangeiro tem qualquer coisa de criança. É ingênuo, é ignorante, é capaz de surpreender, improvisar e sobretudo ver o que os nativos de um lugar, por força (ou fraqueza) do hábito, nâo conseguem mais perceber desde que deixaram de ser crianças. Como está no lugar "do outro", o estrangeiro interpreta tudo à sua própria maneira e, nesses percalços, frequentemente revela ao autóctone novos elementos de sua (do autóctone) velha terra.

O fundamental é que os estrangeiros veem "de dentro" como se estivessem "de fora", o que só é possível porque o espírito tem um delay fantástico em comparaçáo ao corpo: podemos nos deslocar fisicamente o quanto quisermos (considerando, claro, as limitaçôes logístico-financeiras disso), mas a adaptaçăo espiritual năo depende da nossa vontade. Em outras palavras, a maneira como percebemos psicologicamente um lugar ou uma situaçấo, embora necessite de muita (boa) vontade, năo depende só dela. Conforme a expressăo popular, "tu podes sair da tua terra, mas a tua terra nunca vai sair de ti". Mais amplamente: "quanto mais longe tu fores, mais perto tu vais ficar de ti mesmo".

O espírito rejuvenesce no distanciamento, enquanto que o corpo só pode envelhecer e sentir cada vez mais cansaço. Isso se deve à condiçấo de aprendizagem constante - aprendizado da língua estrangeira, dos hábitos, dos diferentes pontos de vista etc. A situaçăo inquietante de deslocamento beneficia o espírito, estimula-o a se renovar, enquanto que o efeito sobre o corpo é mais da ordem da fadiga, do excesso de cansaço exigido pela adaptaçăo ao lugar e ao tempo estrangeiro. Um dia pode durar uma semana, uma semana pode valer um mês, e um mês pode passar como um ano quando estamos no estrangeiro. Essa sensaçâo se deve à enxurrada de novidades que o desconhecido oferece. Uma situaçáo ideal para artistas e curiosos em geral.

O forasteiro năo pode ter

repúdio ao novo: aquela preguiça de aceitar o estrangeiro com calma e em ordem, prestando atençăo aos outros e năo a nós. Faz-se necessária, quando em terras alheias, uma disciplina no sentir e no pensar. [...] Faz-se necessário compreender os termos da cidade oferecida e, dentro deles, colocarmos nossa sensibilidade. Em suma: năo ter preconceitos (LESSA, 1999, p. 79).

As possibilidades săo infinitas, e os limites (espaciais, temporais etc.) evitam a dispersâo das iniciativas. Por exemplo, ter dois amigos permite que nos aprofundemos nessas amizades, enquanto que, se tivermos dez, náo encontraremos nunca tempo para conhecê-los a todos de maneira razoável. 
Os estrangeiros apresentados pelas obras em questâo têm muito em comum. Além do fato de fazerem, por assim dizer, uma espécie de intercâmbio de países, eles demonstram ter um caráter similar. Titino, por exemplo, se encanta com o modo de vida tribal, mais solidário e humanizador do que o estilo "civilizado". Da mesma forma, Fausto Di Salvio aprende outra maneira de ver o mundo e as pessoas com sua aventura em terra estranha, e fica realmente tentado pela possibilidade de começar sua vida de novo. Essa solidariedade humana é exatamente o que o poeta guerrilheiro espera de seu povo, reconhecendo, no exílio, traços históricos que comprovam a força do desejo de ser livre. Quer dizer, ser estrangeiro é universal, independe do lugar de onde se parte e de onde se chega. Ser estranho/estrangeiro náo é nada mais do que ser gente em busca de dignidade e de liberdade. 


\section{REFERÊNCIAS BIBLIOGRÁFICAS}

ANDRADE, Francisco Fernando da Costa. Tempo angolano em Itália. Săo Paulo: FelmanRego, 1963.

BOLATTI, Giulio. L'italiano. Il carattere nazionale come storia e come invenzione. Einaudi, 1983. Traduçấo minha.

Disponível em: http/www.grupposociologia.altervista.org/files/BOLLATI-CARATTERE. pdf.

Acesso em 08/08/2013, às 20:16.

COSTA, José Francisco. Poesia africana de língua portuguesa. 2006. Disponível em http://www.cronopios.com.br/site/ensaios.asp?id=1208. Acesso em 23/09/2013, às 19:43.

CRUZ, Viriato da. Mamá negra (canto da esperança). 2013. Disponível em http://www. lusofoniapoetica.com/artigos/angola/viriato-da-cruz/mama-negra.html. Acesso em 24/09/2013, às 21:13.

FIGUEIREDO, Eurídice; PORTO, Maria Bernadette Velloso (Orgs.). Figuraçóes da alteridade. Niterói: EdUFF/ABECAN, 2007.

KRISTEVA, Júlia. Estrangeiros para nós mesmos. Rio de Janeiro: Rocco, 1994.

LESSA, Ivan. Ivan vê o mundo: crônicas de Londres. Rio de Janeiro: Objetiva, 1999.

NETO, Agostinho. Sagrada esperança. Lisboa: Sá da Costa, 1974.

PATERSON, Janet M. Diferença e alteridade: questóes de identidade e de ética no texto literário. In: Figuraçôes da Alteridade. Org. FIGUEIREDO, Eurídice e PORTO, Maria Bernadette Velloso. Niterói: EdUFF, 2007.

PORTO, Maria Bernadette Velloso. Andarilhos, vagabundos e mendigos: desvios, devires e lugares da alteridade. In: Figuraçóes da Alteridade. Org. FIGUEIREDO, Eurídice e PORTO, Maria Bernadette Velloso. Niterói: EdUFF, 2007.

SANTOS, Diogo Emanuel Gonçalves Nogueira dos. A Mensagem angolana. 2013. Disponível em http://pt.scribd.com/doc/95684764/A-Mensagem-Angolana-1951. Acesso em 24/09/2013, às 20:32. 